\title{
Torilis japonica extract-generated intracellular ROS induces apoptosis by reducing the mitochondrial membrane potential via regulation of the AMPK-p38 MAPK signaling pathway in HCT116 colon cancer
}

\author{
GUEN TAE KIM ${ }^{1}$, SE HEE LEE $^{2}$ and YOUNG MIN KIM ${ }^{1}$ \\ ${ }^{1}$ Department of Biological Sciences, College of Life Science and Nano Technology, Hannam University; \\ ${ }^{2}$ Pharma-gene Inc., Yuseong-gu, Daejeon 305-811, Republic of Korea
}

Received April 5, 2016; Accepted May 24, 2016

DOI: $10.3892 /$ ijo.2016.3578

\begin{abstract}
Torilis japonica extract (TJE) has been reported to possess diverse medicinal properties including anti-inflammatory and antibacterial activities. However, the precise mechanism of its anticancer effect is not understood. Thus, we evaluated the apoptotic effects of TJE and examined its underlying molecular mechanisms in HCT116 colorectal cancer cells. Our results show that TJE induces apoptosis through the generation of intracellular reactive oxygen species (ROS), and that it regulates the mitochondrial outer membrane potential via the AMPK/p38 MAPK signaling pathway. Importantly, $\sim 50 \%$ of cancer cells have p53 mutations. Thus, the ability to induce apoptosis in a p53-independent manner would be of great value in cancer treatment. Our results show that not only does TJE regulate the AMPK/p38 signaling pathway, but it induces apoptosis in cells in which p53 has been knocked down using siRNA. Moreover, as in in vitro studies, TJE induced apoptosis and regulated apoptosis related-proteins in an HCT 116 xenograft model. Taken together, our results demonstrate that TJE, a natural compound that may provide a substitute for chemotherapeutic drugs, has potential as an anticancer agent.
\end{abstract}

\section{Introduction}

The incidence of cancer continues to increase, largely because of an aging population and increasing rates of cancer-causing behaviors and conditions, particularly smoking and obesity. Colorectal cancer is the third most common cancer in males

Correspondence to: Professor Young Min Kim, Department of Biological Sciences, College of Life Science and Nano Technology, Hannam University, Yuseong-dero 1646, Yuseong-gu, Daejeon 305-811, Republic of Korea

E-mail: kym@hnu.kr

Key words: Torilis japonica, apoptosis, reactive oxygen species, mitochondria membrane potential and the second most common in females, with over 1.2 million new cases and 608,700 deaths in $2008(1,2)$. The incidence of colorectal cancer is higher in Westernized areas such as New Zealand, Europe and North America than in Asian countries. However, incidence rates are rapidly increasing in several East Asian countries such as Japan, China and Singapore (3-5). The trend is thought to reflect a change in dietary patterns (6-8). For this reason, interest in alternative medicine for the prevention and treatment of colorectal cancer has increased and research on the effects of various food extracts on colorectal cancer is in progress $(8,9)$.

Inducing apoptosis is one therapeutic strategy in cancer treatment. Apoptosis is the process of programmed cell death. In contrast to necrosis, which is a caused by acute cellular injury, apoptosis has many biological advantages. For example, the separation of fingers and toes in a developing human embryo occurs because cells between the digits undergo apoptosis $(10,11)$. Understanding apoptosis in disease conditions is very important as it not only offers insights into the pathogenesis of a disease but may also give clues as to how the disease can be treated. Numerous research studies have demonstrated the death of cancer cells through apoptosis and compounds have been developed to take advantage of this knowledge $(7,9,12,13)$.

Induction of apoptosis in cancer cells is driven by a complex interplay between several proteins. Members of the Bcl-2 family of proteins are key regulators of apoptosis. These proteins are known to regulate mitochondrial function and control the release of apoptosis-inducing factors such as cytochrome $c$ from the mitochondrial inter-membrane space (14-16). The anti-apoptotic proteins Bcl-2 and Mcl-1 are predominantly found in the mitochondria; they inhibit apoptosis by suppressing the release of cytochrome $c(17,18)$. In contrast, the pro-apoptotic proteins Bax, Bak and PUMA mainly induce the release of stimulators of apoptosis and bring about mitochondrial dysfunction after translocating to the mitochondrial outer membrane (19-21). In particular, translocation of Bax and Bak to the mitochondrial outer membrane is required for the release of cytochrome $c$ during apoptosis. Bax and Bak undergo homo- and hetero-oligomerization and bind to the mitochondrial outer membrane. These protein 
complexes trigger cytochrome $c$ release into the cytosol by reducing mitochondrial outer membrane permeabilization (22-25). Cytochrome $c$ induces apoptosis by increasing the activity of caspases in the cytoplasm (26). Control of this process using targeted compounds is very important in cancer treatment.

The fruit of Torilis japonica can be used as a substitute for She chuang zi, which is a traditional Chinese medicine prescribed as an anti-allergenic, anti-fungal, anti-bacterial and sedative agent. Previously, we found that a 95\% ethanol extract from Torilis japonica had beneficial effects on metastasis through regulation of the EGFR signaling pathway in MCF-7 breast cancer cells (27). However, its anti-proliferative and apoptosis-inducing effects have not yet been elucidated.

In this study, we investigated the effects of Torilis japonica extract (TJE) extracted from the fruit of Torilis japonica on apoptosis in HCT116 and HT-29 colon cancer cells. TJE induced apoptosis through the generation of intracellular reactive oxygen species (ROS) and a reduction in the mitochondrial membrane potential via regulation of the AMPK/p38 MAPK signaling pathway. Moreover, the apoptotic effects of TJE persisted in cells lacking p53. Taken together, our results indicate that TJE may be a novel natural ingredient for cancer therapy that decreases the mitochondrial membrane potential of colorectal cancer cells, thereby inducing apoptosis.

\section{Materials and methods}

Plant material and preparation of TJE. Dried whole fruit of Torilis japonica was purchased from Na-num Pharmacy (Kyung-buk, Korea). Plant material (200 g) was extracted two times with $95 \%$ ethanol at room temperature for 3 day and was subsequently filtered. The combined filtrate was concentrated under vacuum at $60^{\circ} \mathrm{C}$, and completely dried by freeze drying. The yield was $10 \%$ and TJE powder was dissolved in DMSO and filtrated by $0.2 \mu$ pore size filter for in vitro studies.

Reagent. N-acetyl cystein (NAC), 4,5-dimethylthiazol2-yl)-2,5-diphenyltetrazolium bromide (MTT), DCFH-DA are purchased from Sigma-Aldrich (St. Louis, MO, USA). FITC-Annexin V apoptosis detection kit is obtained from BD Pharmingen (San Diego, CA, USA). Mitotracker was purchased from Molecular Probes (Eugene, OR, USA). Specific anti-bodies that recognized p-AMPK $\alpha 1$, AMPK $\alpha 1, p 38, p-p 53$, caspase-3, Bcl-2, Mcl-1, COX-4, $\beta$-actin are obtained from Cell Signaling Technology (Beverly, MA, USA) and Bax, Bak, PUMA, p-p38 MAPK, p53, cytochrome $c$ are purchased from Santa Cruz Biotechnology, Inc. (Dallas, TX, USA).

Cell culture. HCT116 and HT-29, fibroblast cells were obtained from the American Type Culture Collection (ATCC, Rockville, MD, USA) 3 month before experiment begun. HCT116, HT-29 cells were grown in RPMI-1640 medium and fibroblast cells were grown in DMEM medium containing $10 \%$ fetal bovine serum (both from HyClone, Waltham, MA, USA) and $1 \%$ antibiotics (100 mg/l streptomycin, $100 \mathrm{U} / \mathrm{ml}$ penicillin) at $37^{\circ} \mathrm{C}$ in a $5 \% \mathrm{CO}_{2}$ atmosphere. Cells were suspended by Trypsin-EDTA (HyClone) and separated $1.5 \times 10^{5} / \mathrm{ml}$ at each plates, every $48 \mathrm{~h}$. All the cell lines were authenticated by each 6 month repeat analysis at Korea Cell Line Bank (KCLB, Seoul, Korea)
Detection of intracellular ROS by fluorescence microscope. Cells were seeded $1 \times 10^{5} / \mathrm{ml}$ in 12 -well plate with cover glasses. After treatment the indicated time and dose at $37^{\circ} \mathrm{C}$ in a $5 \% \mathrm{CO}_{2}$ atmosphere, the cells were incubated with $10 \mu \mathrm{M}$ of DCFH-DA for $30 \mathrm{~min}$ and fixed with $3.7 \%$ formaldehyde for $20 \mathrm{~min}$. Cells were washed with phosphate-buffered saline (PBS) twice and fluorescence was detected by fluorescence microscope (Carl Zeiss, Thornwood, NY, USA).

Measurement of intracellular ROS levels. Cells were seeded $1 \times 10^{6} / \mathrm{ml}$ in $100 \mathrm{~mm}$ plate and incubated for $24 \mathrm{~h}$. After incubation, cells treated with test compound for $6 \mathrm{~h}$ at $37^{\circ} \mathrm{C}$ in a $5 \% \mathrm{CO}_{2}$ atmosphere. Cells were incubated with $40 \mu \mathrm{M}$ of DCFH-DA for $30 \mathrm{~min}$ and harvested by trypsinization, collected by centrifugation, washed with PBS twice, and resuspended in PBS. Fluorescence intensity were analyzed by using flow cytometer (Becton-Dickinson Biosciences, Franklin Lakes, NJ, USA).

Cell proliferation assay (MTT). Cells were seeded at 4,000/ml each well in 96-well plate, and incubated $24 \mathrm{~h}$. After the incubation, treated with test compound and incubate at $37^{\circ} \mathrm{C}$ in a $5 \% \mathrm{CO}_{2}$ atmosphere. After $24 \mathrm{~h}$, cells were incubated with $20 \mu \mathrm{MTT}$ ( $5 \mathrm{mg} / \mathrm{ml}$ with PBS) solution for $1 \mathrm{~h}$. Optical densities of solution, in each well, were determined by Microplate reader (Bio-Rad Laboratories, Inc., Tokyo, Japan) at $595 \mathrm{~nm}$.

Determination of apoptosis by Annexin V/PI staining analysis. Cells were seeded at $1 \times 10^{6} / \mathrm{ml}$ in $100 \mathrm{~mm}$ plate and incubated for $24 \mathrm{~h}$. After incubation, cells treated with test compound for $24 \mathrm{~h}$ at $37^{\circ} \mathrm{C}$ in a $5 \% \mathrm{CO}_{2}$ atmosphere. Total cells were harvested by trypsinization, collected by centrifugation, washed with PBS, and resuspended in binding buffer. Cells were stained with Annexin V and PI for 15 min. Fluorescence intensity were analyzed by using flow cytometer (BD Biosciences).

Measurement of mitochondria membrane potential. Cells were seeded at $1 \times 10^{6} / \mathrm{ml}$ in $100 \mathrm{~mm}$ plate and incubated for $24 \mathrm{~h}$. After incubation, cells treated with test compound for $24 \mathrm{~h}$ at $37^{\circ} \mathrm{C}$ in a $5 \% \mathrm{CO}_{2}$ atmosphere. Total cells were harvested by trypsinization, collected by centrifugation, washed with PBS. Cell were incubated with JC-1 for $30 \mathrm{~min}$ $37^{\circ} \mathrm{C}$ in a $5 \% \mathrm{CO}_{2}$ atmosphere before the flow cytometer analysis (BD Biosciences).

Caspase-3 activity assay. We used caspase-3 activity assay kit (Abcam PLC, Cambridge, UK). Cells were seeded at $1 \times 10^{6} / \mathrm{ml}$ in $100 \mathrm{~mm}$ plate and incubated for $24 \mathrm{~h}$. After incubation, cells treated with test compound for $24 \mathrm{~h}$ at $37^{\circ} \mathrm{C}$ in a $5 \% \mathrm{CO}_{2}$ atmosphere. Total cells were harvested by trypsinization, collected by centrifugation, washed with PBS. Cells were resuspended in lysis buffer and mixed with $2 \mathrm{X}$ reaction buffer. Samples were reactivated with DEVD-p-NA for $2 \mathrm{~h}$ at $37^{\circ} \mathrm{C}$. Optical densities of solution, in each well, were determined by Microplate reader (Bio-Rad Laboratories, Inc.) at $405 \mathrm{~nm}$.

Fraction of mitochondria and cytosol proteins. We used Mitochondria/Cytosol Fraction kit (Abcam PLC). Cells were seeded at $1 \times 10^{6} / \mathrm{ml}$ in $100 \mathrm{~mm}$ plate and incubated for 
$24 \mathrm{~h}$. After incubation, cells were treated with test compound for $24 \mathrm{~h}$ at $37^{\circ} \mathrm{C}$ in a $5 \% \mathrm{CO}_{2}$ atmosphere. Total cells were harvested by trypsinization, collected by centrifugation, washed with PBS, and homogenized in ice-cold cytosol extraction buffer mix containing DTT and protease inhibitor using a sonicator. The homogenates were centrifuged at $3,000 \mathrm{rpm}$ for $10 \mathrm{~min}$ at $4^{\circ} \mathrm{C}$ and supernatants were collection. Supernatant were centrifuged at $13,000 \mathrm{rpm}$ for $30 \mathrm{~min}$ at $4^{\circ} \mathrm{C}$ and collected supernatant for cytosol proteins and pellets were resuspended with ice cold mitochondria extraction buffer containing DTT and protease inhibitor for mitochondria proteins.

Protein oligomerization. Bak and Bax oligomerization were assessed by chemical crosslinking. Briefly, mitochondria protein fractions were resuspended in conjugation buffer. For disulphide-bond formation, mitochondria protein fractions were incubated with the bis(maleimido)hexane (Thermo Fisher Scientific, Rockford, IL, USA) for $1 \mathrm{~h}$ at room temperature and the samples analyzed by non-reducing SDS-PAGE.

Immunoprecipitation (IP) assay. We used to surebead protein $\mathrm{G}$ magnetic beads kit (Bio-Rad Laboratories, Inc., Hercules, CA, USA). Cells were seeded at $1 \times 10^{6} / \mathrm{ml}$ in $100 \mathrm{~mm}$ plate and incubated for $24 \mathrm{~h}$. After incubation, cells were treated with test compound for $24 \mathrm{~h}$ at $37^{\circ} \mathrm{C}$ in a $5 \% \mathrm{CO}_{2}$ atmosphere. Mitochondria/cytosol proteins were fraction and mitochondria proteins were incubated with specific antibody bound magnetic bead. The beads were washed using a magnet and PBS. Target proteins were elusion in $1 \mathrm{X}$ sample buffer and analyzed by western blotting.

Bcl-2 activation assay. We used Muse Bcl-2 activation dual detection kit (Merck Milipore, Darmstadt. Germany). Cells were seeded at $1 \times 10^{5} / \mathrm{ml}$ in 6 -well plate and incubated for $24 \mathrm{~h}$. After incubation, cells were treated with test compound for $24 \mathrm{~h}$ at $37^{\circ} \mathrm{C}$ in a $5 \% \mathrm{CO}_{2}$ atmosphere. Total cells were harvested by trypsinization, collected by centrifugation, washed with PBS. Cell were fixed and permeabilized by reagent in the kit. The antibody, which was combined with fluorescence tag, was reacted for $1 \mathrm{~h}$ at room temperature with slow agitation, and it was washed once with the assay buffer. Cells were resuspended in assay buffer and analyzed by Muse cell analyzer.

Transient transfection with small interfering RNA. Small interfering RNA (siRNA) was purchased by Dharmacon (Chicago, IL, USA). For transient transfection, cells were seeded at $5 \times 10^{3} / \mathrm{ml}$ on a 6 -well plate with antibiotics free medium. After incubation overnight, targeting siRNA was transfected using DharmaFECT2 transfection reagent (Dharmacon) according to manufacturer's instructions. After incubation for $72 \mathrm{~h}$, cells were treated with TJE with NAC at indicated doses.

Western blotting. Cells were seeded at $1 \times 10^{5} / \mathrm{ml}$ in a 6 -well plate and incubated for $24 \mathrm{~h}$, and after the incubation, treated with test compound for $6 \mathrm{~h}$ at $37^{\circ} \mathrm{C}$ in a $5 \% \mathrm{CO}_{2}$ atmosphere. Cells were rinsed twice with ice-cold PBS and scraped with lysis buffer (50 mM Tris- $\mathrm{HCl} \mathrm{pH} 8.0,150 \mathrm{mM} \mathrm{NaCl}, 1 \% \mathrm{NP}-40$, $0.5 \%$ sodium deoxycholate, $1 \mathrm{mM}$ PMSF) and subjected to western blot analysis. First antibody was reacted overnight at $4^{\circ} \mathrm{C}$ and second antibody for $75 \mathrm{~min}$ at room-temperature with slow agitation.

Immunofluorescence (IF) staining. Cells were seeded $1 \times 10^{5} / \mathrm{ml}$ in a 12-well plate with cover glasses. After treatment with the indicated time and dose, the cells were stained with mitotracker for $30 \mathrm{~min}$ at $37^{\circ} \mathrm{C}$ in a $5 \% \mathrm{CO}_{2}$ atmosphere. Cells were fixed with $3.7 \%$ formaldehyde for $20 \mathrm{~min}$ and pemeabilized with $0.2 \%$ Triton X-100 for 20 min. Cells were washed with PBS twice and reacted with cytochrome $c$ antibody overnight at $4^{\circ} \mathrm{C}$. Cells were washed with PBS twice and reacted with secondary antibody for $1 \mathrm{~h}$. Fluorescence was detected by confocal (Olympus, Tokyo, Japan).

Xenograft model. Five-week-old male Balb/c nu/nu mice were obtained from SLC (Tokyo, Japan) and housed in sterile filer-topped cages. For tumor induction, HCT116 human colon cancer cells $\left(2.5 \times 10^{5}\right.$ cells $\left./ 0.1 \mathrm{ml}\right)$ were subcutaneously injected into the left flank of the mice (each group had 5 animals). One week after the injection of cells, they were co-treated with TJE $80 \mathrm{mg} / \mathrm{kg} / \mathrm{day}$ for 21 days. Tumor size was measured using a caliper at 2 day intervals, and the volume was calculated by the modified formula $\mathrm{V}=1 / 2$ (length $\mathrm{x}$ width $^{2}$ ). After the 3 -week treatment, tumor was removed and frozen in liquid nitrogen for western blot analysis or fixed with formalin for immunohistochemistry and H\&E staining. All animal experiments were approved by the Ethics Committee for Animal Experimentation, Hannam University.

Immunohistochemistry. Tumor specimens from mice were fixed in $10 \%$ formaldehyde, embedded in paraffin and sectioned into $5 \mu \mathrm{m}$ thick slices. Consecutive thin cryosections $(5 \mu \mathrm{m})$ of OCT compound (Sakura Finetek, Torrance, CA, USA) embedded tumor tissues were fixed in acetone at $4^{\circ} \mathrm{C}$ for $10 \mathrm{~min}$. After washing in PBS, sections were treated with $3 \% \mathrm{H}_{2} \mathrm{O}_{2}$ for 10 min to block endogenous peroxidase activity, and the sections were blocked with normal rabbit serum. Then, the sections were blocked and washed in PBS and incubated with specific antibody overnight at $4^{\circ} \mathrm{C}$. Negative controls were incubated with the primary normal serum $\operatorname{IgG}$ for the species from which the primary antibody was obtained.

TUNEL assay. Levels of apoptosis in distal colon tissue were determined using the TdT-mediated dUTP nick-end labeling (TUNEL) method. Tumor specimens from mice were fixed in $10 \%$ formaldehyde, embedded in paraffin and sectioned into $5 \mu \mathrm{m}$ thick slices. Tissue sections were processed according to manufacturer's instructions for the ApopTag peroxidase in situ apoptosis detection kit (Vector Laboratories, Burlingame, CA, USA).

Statistical analysis. Cell viability and caspase-3 activity was statistically analyzed using unpaired t-test (SPSS, Chicago, IL, USA). $\mathrm{P}<0.05$ was considered statistically significant.

\section{Results}

TJE suppresses cancer cell proliferation and induces apoptosis by reducing the mitochondrial membrane potential. We 
A

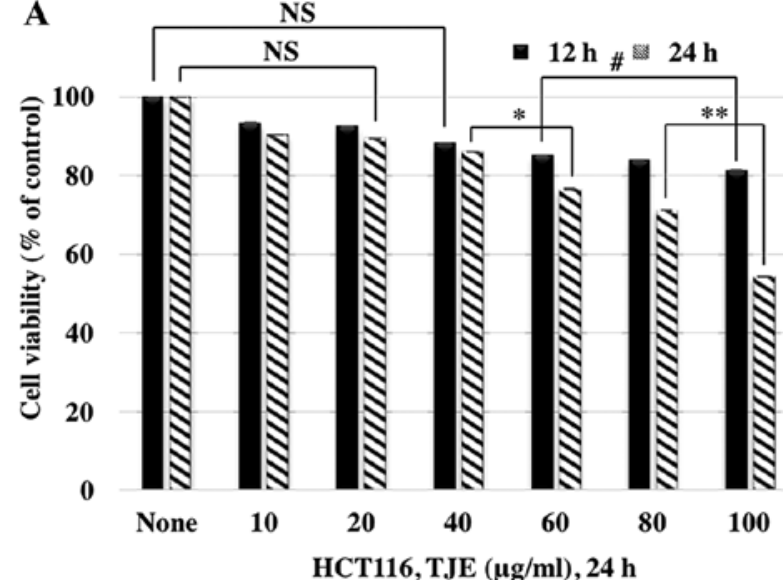

B

120

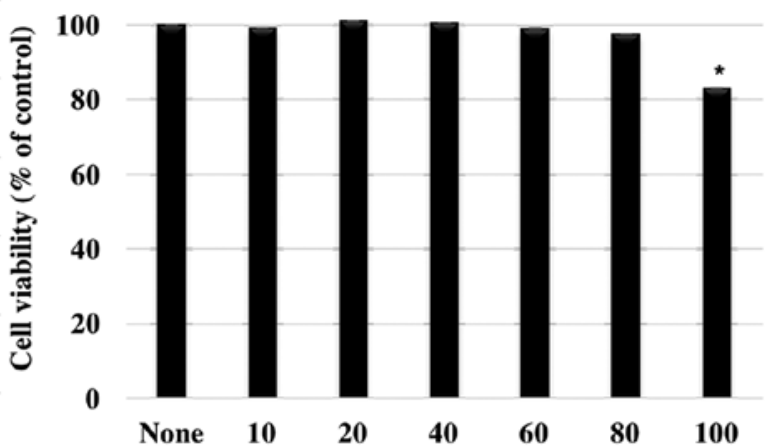

Fibroblast, TJE $\mu \mathrm{g} / \mathrm{ml}, 24 \mathrm{~h}$

C

TJE, HCT116, 24 h

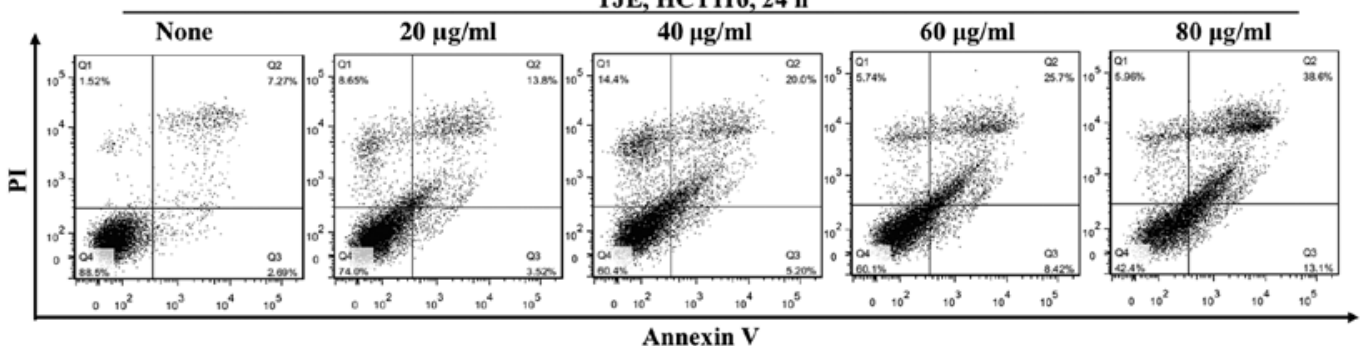

D TJE, HCT116, $24 \mathrm{~h}$

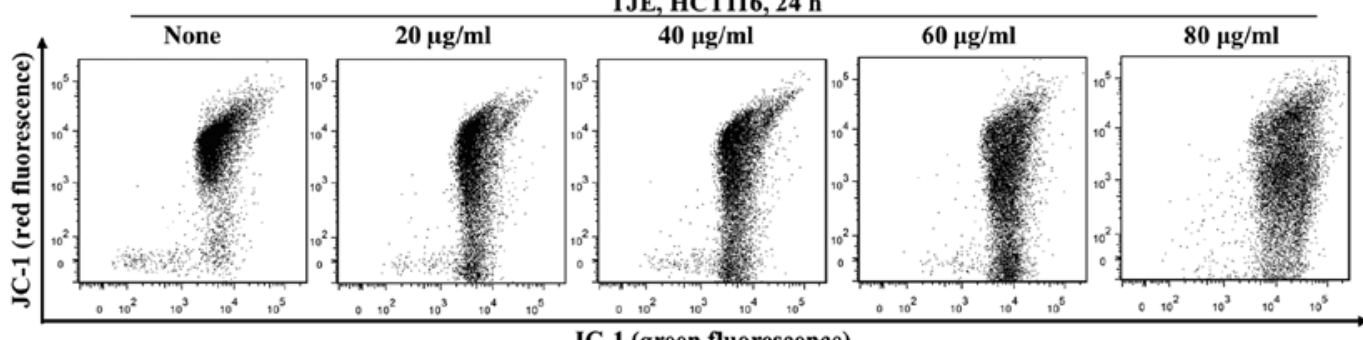

JC-1 (green fluorescence)

Figure 1. TJE induces apoptotic cell death by controlling mitochondria outer membrane potential. (A and B) Cell viability was measured by MTT assay. Cells were treated with the indicated concentration of TJE for 12 and $24 \mathrm{~h}$ for HCT116 colon cancer cells and $24 \mathrm{~h}$ for fibroblast. ${ }^{~} \mathrm{P}<0.05$ compared to $12 \mathrm{~h}$ sample control. ${ }^{*} \mathrm{P}<0.05$ and ${ }^{* *} \mathrm{P}<0.01$ compared to $24 \mathrm{~h}$ sample control. NS, not significant (each experiment's $\mathrm{n}=3$ ). (C) Cells were treated with the indicated concentration of TJE for $24 \mathrm{~h}$, and it was stained with Annexin V/PI for measured of apoptotic cell death, and fluorescence intensity was measured by flow cytometry. (D) Cell were stained with JC-1 to evaluate mitochondria outer membrane potential, and fluorescence intensity was measured by flow cytometry.

investigated the anti-proliferative and apoptotic effects of TJE. We treated cells with TJE (10-100 $\mu \mathrm{g} / \mathrm{ml})$ for 12 and $24 \mathrm{~h}$, and then assayed for cellular viability and apoptosis. Cells treated with TJE showed a decrease in viability and an increase in the number of Annexin V-positive cells in a dose-dependent manner. In normal human fibroblasts, however, TJE had no effect on cellular viability (Fig. 1A-C).

To understand the mechanism by which TJE induces apoptosis, we measured the mitochondrial membrane potential after treatment with different concentrations of TJE via JC-1 staining (Fig. 1D). Our results showed that TJE reduced the membrane potential dose-dependently.

TJE regulates $p 53$ and AMPK expression, $p 38$ activation and levels of pro-apoptotic proteins. We analyzed the changes in p-AMPK $\alpha 1$, p-p38, p53 and p-p53 levels and the apoptosisrelated proteins Bax, Bak, PUMA, cleaved caspase-3, Mcl-1 and Bcl-2 after treatment with different concentrations of TJE by western blotting. Our results showed that TJE strongly activated AMPK, p38 and p53 dose-dependently (Fig. 2A).
Moreover, TJE reduced the expression of Mcl-1 and Bcl-2 and induced the expression and mitochondrial translocation of Bax, Bak and PUMA. The latter three proteins became localized to the outer membrane of the mitochondria, which led to secretion of cytochrome $c$ from the mitochondria to the cytosol by a reduction in the mitochondrial membrane potential (Fig. 2B and C).

\section{TJE modulates signaling pathways and mitochondrial membrane} potential through generation of intracellular ROS. We examined whether TJE promotes the generation of ROS in HCT116 colon cancer cells. We measured intracellular ROS levels following treatment of cells with TJE $(20-80 \mu \mathrm{g} / \mathrm{ml})$ for $6 \mathrm{~h}$. As shown in Fig. 3A (left panel), TJE increased ROS levels at the indicated concentrations. These effects were completely blocked by co-treatment with NAC, a ROS scavenger (right panel).

To make sure that the increase in intracellular ROS levels was related to TJE-regulated signaling proteins and the induction of apoptosis, we co-treated cells with NAC and then analyzed protein levels and the concentration of 
A

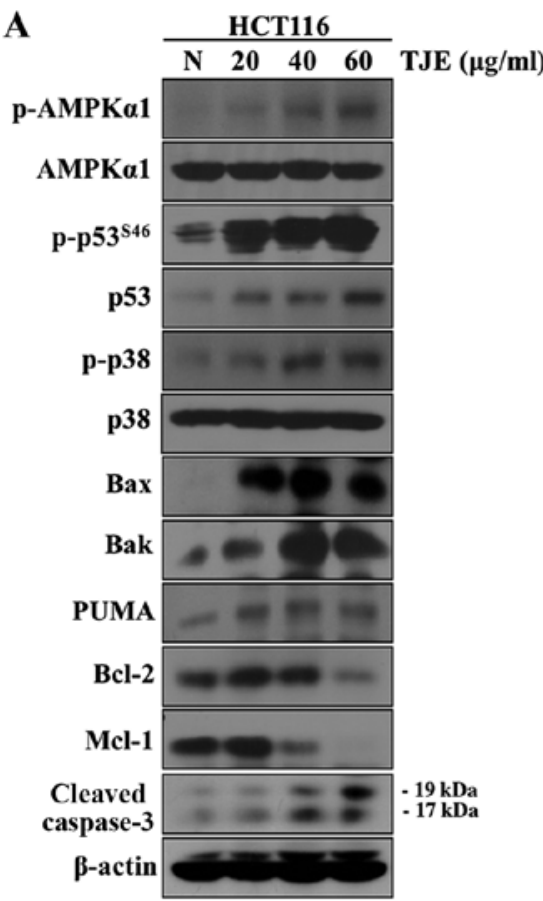

B

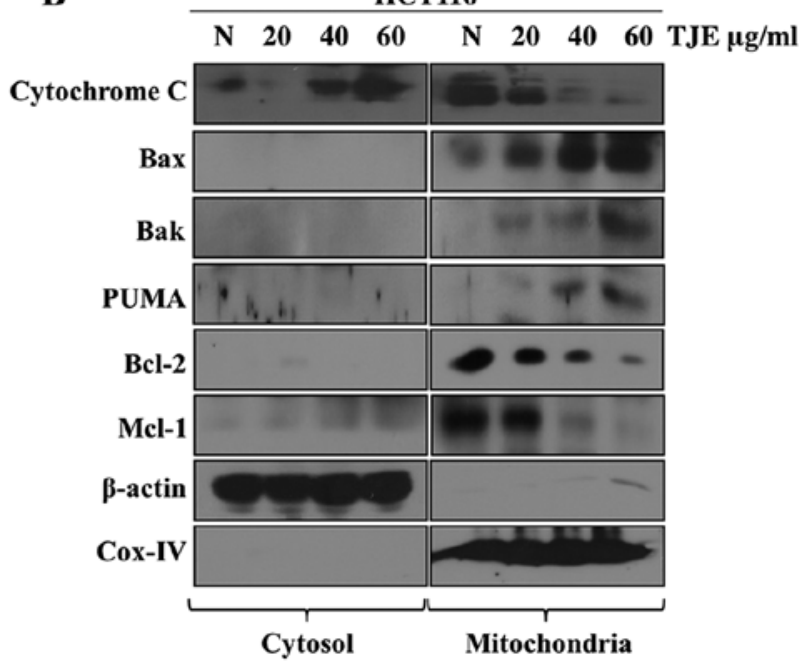

C

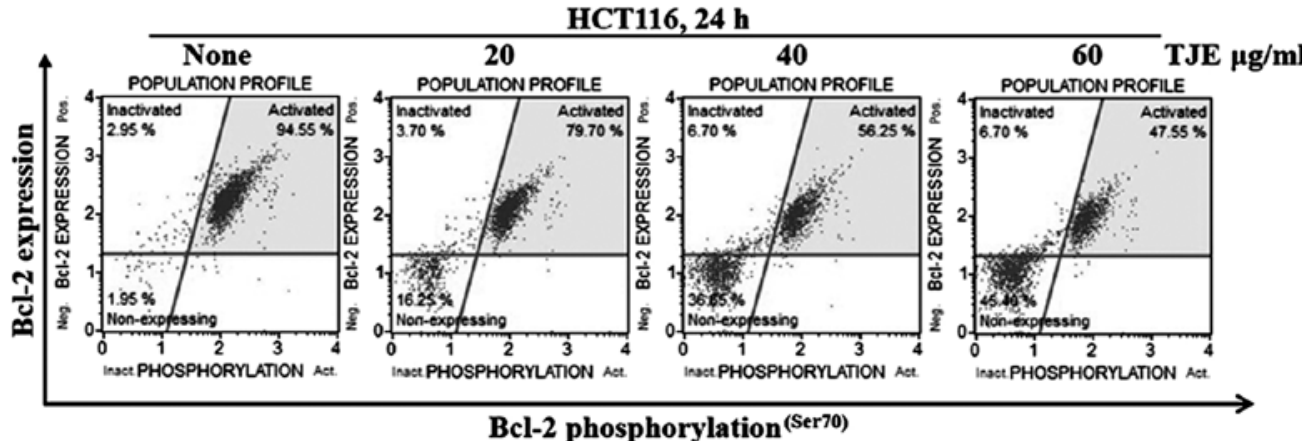

Figure 2. TJE regulates p53 and AMPK expression, p38 activation, and levels of apoptosis related- proteins. (A) Cells were treated with the indicated concentrations of TJE for $6 \mathrm{~h}$. The expression of apoptosis related-proteins and the activation of AMPK 1 , p38, p53 were analyzed by western blotting. (B) Cells were treated with the indicated concentrations of TJE for $24 \mathrm{~h}$. The apoptosis related proteins were separated to mitochondria proteins and cytosol proteins. Protein levels were detected by western blotting. (C) Bcl-2 activation levels were measured by Muse cell analyzer.

Annexin V-positive cells. The cells co-treated with NAC and TJE did not undergo increases in AMPK, p38 or p53 phosphorylation and showed decreased expression, oligomerization, and binding of apoptosis-related proteins and increases in the expression of anti-apoptotic proteins in comparison to cells treated with TJE alone (Figs. 3E and 4). In addition, cells co-treated with TJE and NAC did not undergo cell death and did not exhibit a reduction in the mitochondrial membrane potential (Fig. 3F). By contrast, TJE-treated cells displayed increased levels of apoptotic cell death through changes in the mitochondrial membrane potential which led to secretion of cytochrome $c$ from the mitochondria to the cytosol (Fig. 3G). Generally, cytochrome $c$ in the cytosol initiates caspase cleavage and activates effector caspases such as caspase-3, which in turn induce apoptosis. We demonstrated that TJE induced caspase-3 activation dose-dependently. Co-treatment with NAC abolished this effect (Fig. 3H).

TJE regulates cytochrome $c$ translocation to the cytoplasm. To show that TJE treatment induced cytochrome $c$ release from the mitochondria to the cytosol, we co-treated cells with
TJE and NAC for $24 \mathrm{~h}$ and stained cells in order to visualize the mitochondria and cytochrome $c$. In TJE-treated cells, cytochrome $c$ translocated from the mitochondria to the cytosol; in contrast, in control cells and those co-treated with both TJE and NAC, cytochrome $c$ remained in the mitochondria (Fig. 5).

TJE induces apoptosis via the AMPK/p38 MAPK signaling pathway in a p53-independent manner. In order to identify the intracellular signaling pathway that mediates the effects of TJE, we transfected cells with siRNAs against AMPK, p38 and p53. The cells in which AMPK and p38 were knocked down did not undergo apoptosis following TJE treatment, but the cells treated with p53 siRNA still showed an increase in apoptotic cell death (Fig. 6A). In addition, TJE did not affect caspase-3 activity or cytochrome $c$ translocation in the cells treated with AMPK or p38 siRNA, but did affect those activities in the p53 siRNA-treated group (Fig. 6B).

To confirm that apoptotic cell death following TJE treatment is p53-independent, we analyzed apoptosis-related protein expression and translocation to the mitochondria in HCT116 cells transfected with siRNAs against apoptosis-related 
A

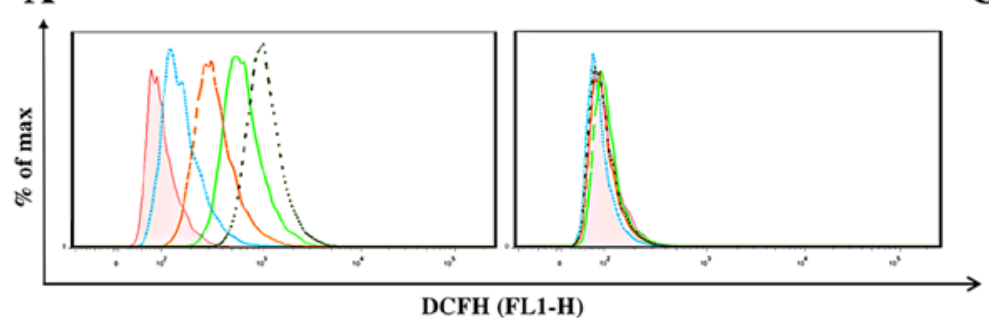

B

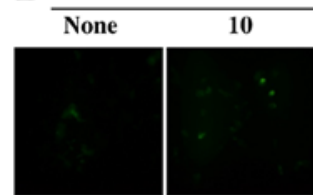

E
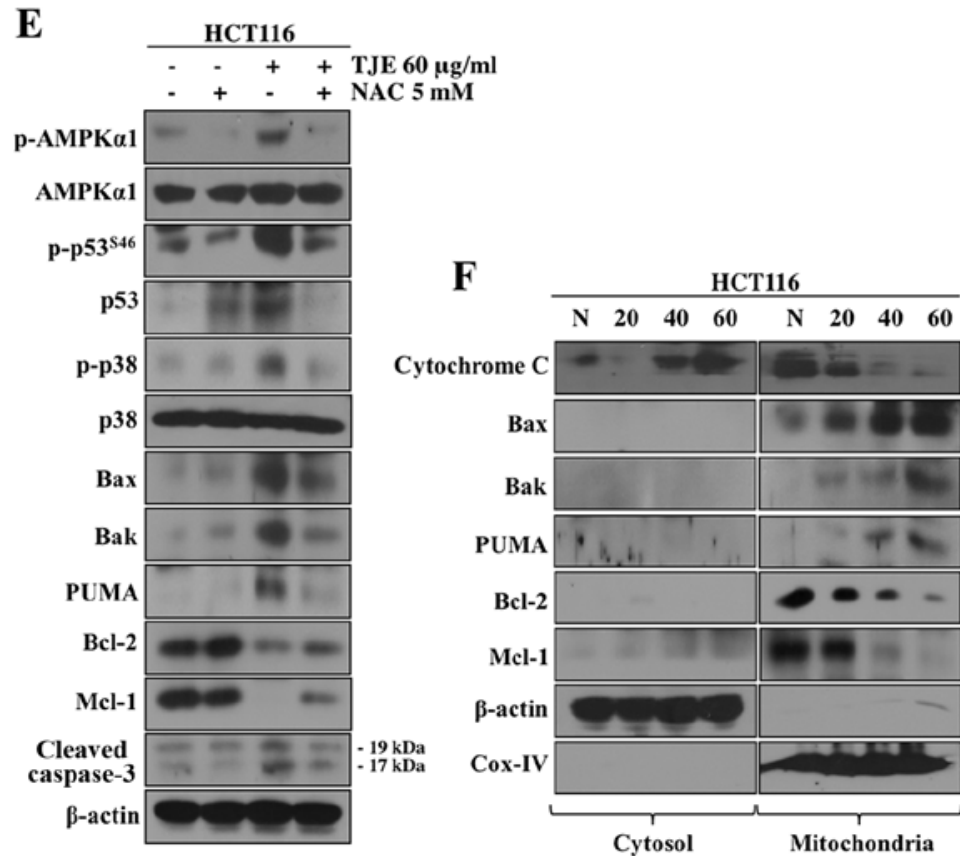

C

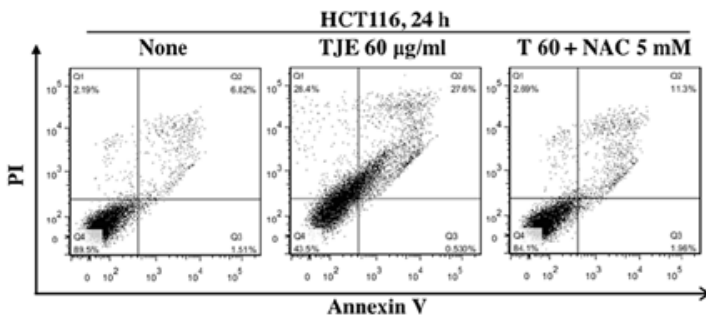

D

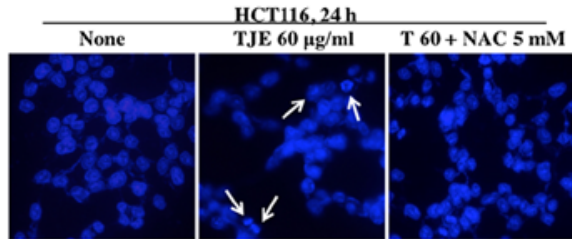

G

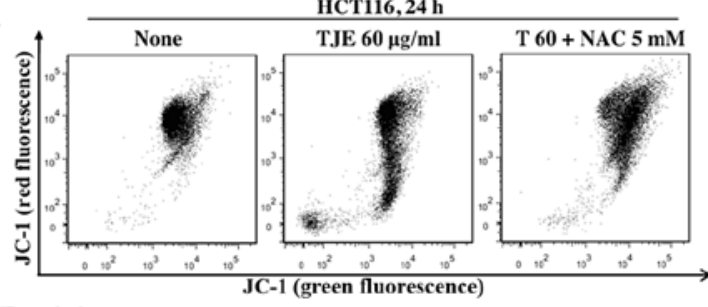

F

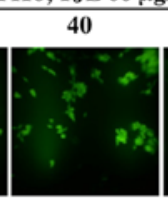

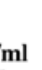

F

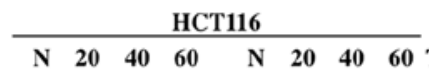

$\mathbf{H}$

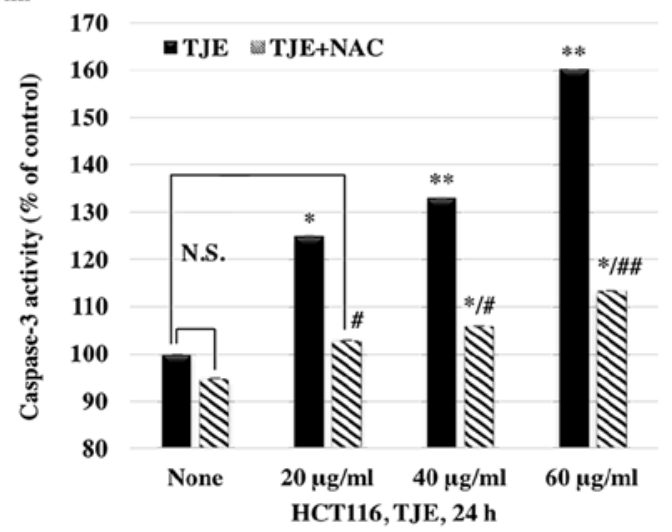

Figure 3. TJE modulates signaling pathways and mitochondrial membrane potential through generation of intracellular ROS. (A) Cells were treated with the indicated concentrations of TJE for $6 \mathrm{~h}$ (left panel), pretreated with $5 \mathrm{mM}$ NAC for $30 \mathrm{~min}$, and then exposed to quercetin (right panel). After $6 \mathrm{~h}$, cells were treated with $40 \mu \mathrm{M}$ DCFH-DA for $30 \mathrm{~min}$, and fluorescence intensity was measured by flow a cytometer. Red line, control; cyan line, TJE $20 \mu \mathrm{g} / \mathrm{ml}$; orange line, TJE $40 \mu \mathrm{g} / \mathrm{ml}$; green line, TJE $60 \mu \mathrm{g} / \mathrm{ml}$; dark green line, TJE $80 \mu \mathrm{g} / \mathrm{ml}$. (B) In addition, cells were treated with the indicated concentrations and times of TJE and fluorescence was detected using a fluorescence microscope. Cells were treated with TJE after pretreatment 5 mM NAC for 30 min. (C) Cells were stained with Annexin V/PI and fluorescence intensity was measured by a flow cytometer. (D) Cells were treated with $10 \mu \mathrm{M}$ Hoechst 33342 for 30 min, and fluorescence was detected using a fluorescence microscope. Arrow indicate apoptotic bodies. (E) The expression of apoptosis related-proteins and the activation of AMPK $\alpha 1$, p38, p53 were analyzed by western blotting. (F) Cell were stained with JC-1 and fluorescence intensity was measured by a flow cytometer. (G) Fraction of mitochondria/cytosol proteins were analyzed by western blotting. $(\mathrm{H})$ Caspase- 3 activities were measured by caspase- 3 activity assay. ${ }^{*} \mathrm{P}<0.05$ and ${ }^{* *} \mathrm{P}<0.01$ compared to control; ${ }^{\#} \mathrm{P}<0.05$ and ${ }^{\# \#} \mathrm{P}<0.01$ compared to TJE treated only groups. NS, not significant (each experiment $\mathrm{n}=3$ ).

proteins. Our results showed that TJE did not induce pro-apoptotic protein expression or downregulation of anti-apoptotic proteins in AMPK siRNA- or p38 siRNA-transfected cells, but the effects of TJE were still seen in p53 siRNA-transfected cells, except those treated with PUMA; PUMA cannot act independently of p53 (Fig. 6C and D). Moreover, TJE induced apoptotic cell death in HT-29 colon cancer cells, which have a mutation in the p53 gene (Fig. 6F).

TJE induces cell death through regulation of intracellular signaling pathways in an HCT116 xenograft model. To analyze the consequences of TJE treatment in an HCT116 xenograft model of tumor growth, we performed histological analysis from control- and TJE ( $80 \mathrm{mg} / \mathrm{kg} / \mathrm{day})$-treated tumor tissue stained with H\&E using the TUNEL assay. The amount of tumor tissue in TJE-treated samples was considerably less than that of control samples (Fig. 7A). The number of TUNEL-positive cells was significantly increased and cancer tissue was degraded in TJE-treated samples (Fig. 7E). In addition, in a similar in vitro experiment, the AMPK/p38 MAPK and p53 signaling pathways were activated, and apoptosisrelated proteins showed an increase in expression and translocation to the cytosol (Fig. 7B-D and F).

\section{Discussion}

The incidence of colorectal cancer has increased because of changes in dietary patterns and lifestyles (1-5). For this reason, 
A
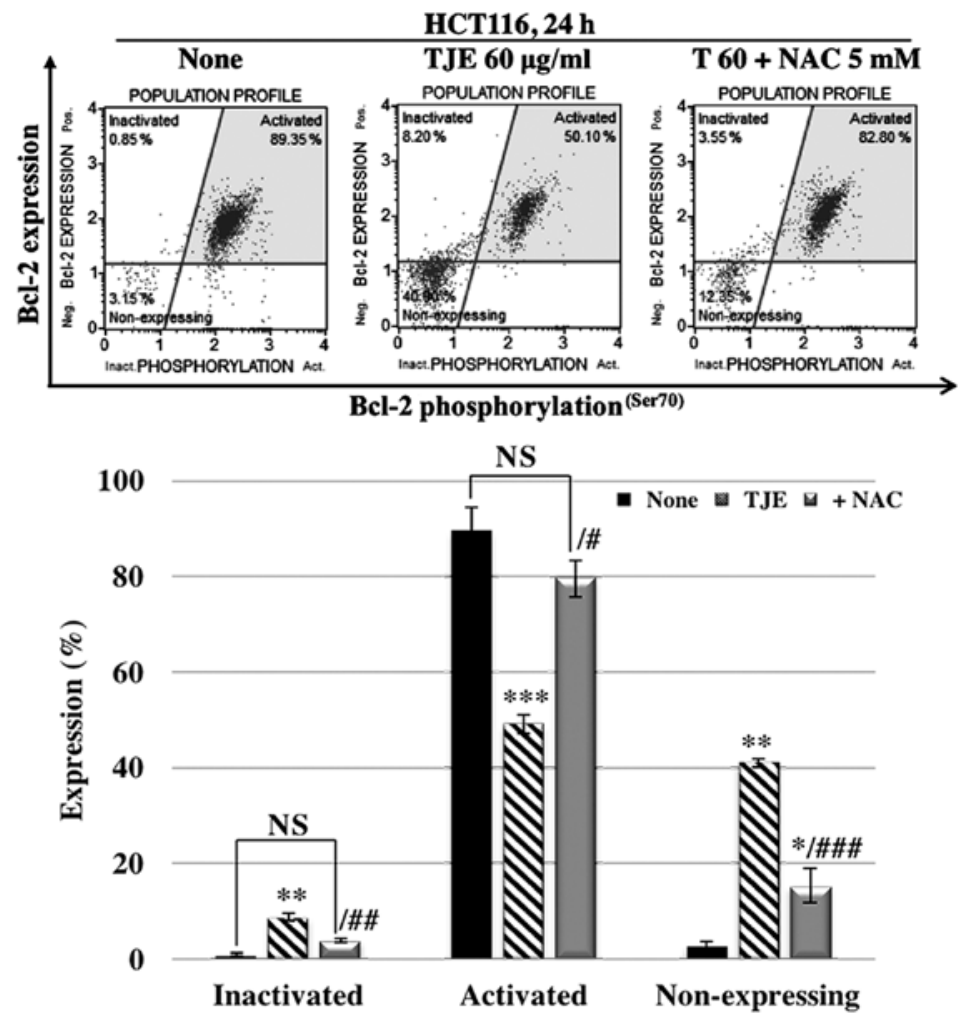

B
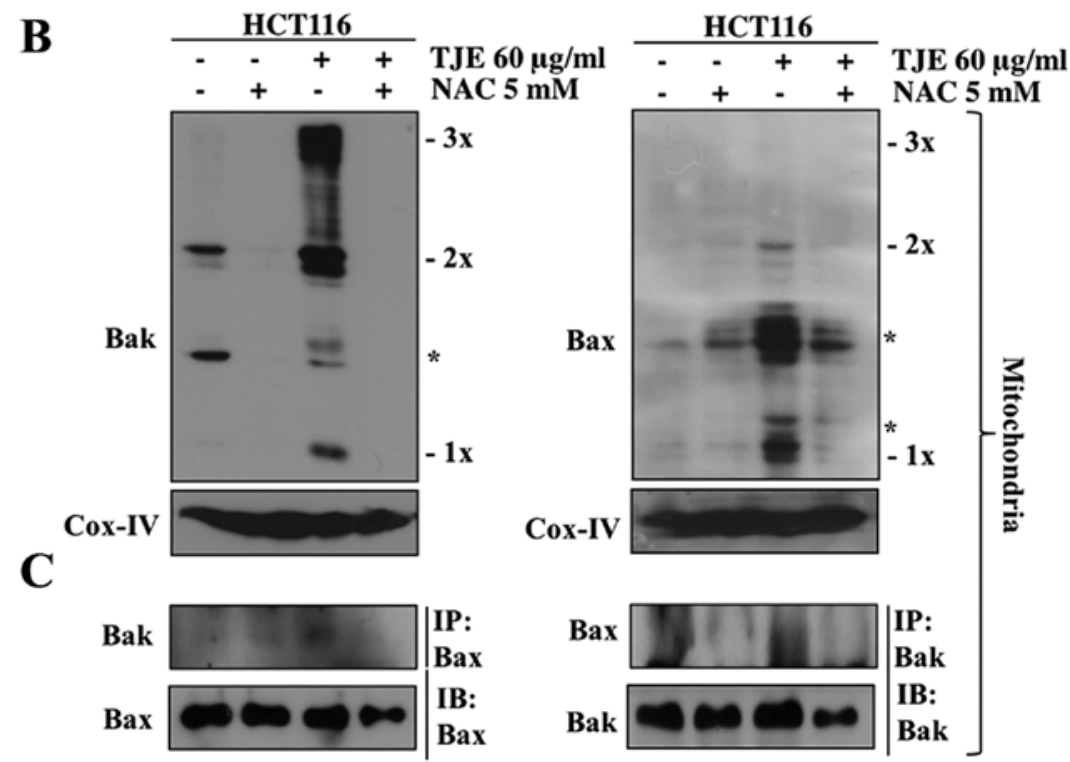

Figure 4. TJE modulates apoptotic cell death related proteins through generation of intracellular ROS. Cells were treated with TJE after pretreatment $5 \mathrm{mM}$ NAC for 30 min (A) Bcl-2 activation levels were measured by Muse cell analyzer. ${ }^{* *} \mathrm{P}<0.01$ and ${ }^{* * *} \mathrm{P}<0.001$ compared to control; ${ }^{*} \mathrm{P}<0.05$, ${ }^{\# \#} \mathrm{P}<0.01$ and

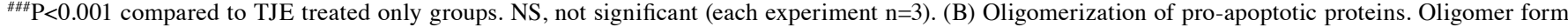
was analyzed by non-ionized gel western blotting. (C) Co-binding of Bax and Bak were detected by immunoprecipitation. Co-binding form was analyzed by non-ionized gel western blotting.

there has been an increased interest in the effect of compounds extracted from natural sources on the prevention and treatment of colorectal cancer. Such compounds induce apoptosis and arrest metastasis through the regulation of intracellular signaling in cancer cells (27-33). Many researchers have identified food extracts that have been used in cancer chemotherapy experiments.

The fruit of Torilis japonica is used as a substitute for She chuang $z i$, which is a traditional Chinese medicine.
Previously, we found that ethanol extracts from the fruit of Torilis japonica arrested abnormal metastasis through regulation of the EGFR signaling pathway in MCF-7 breast cancer cells (27). In this study, we focused on the effects of TJE on the induction of apoptosis through alterations in the mitochondrial membrane potential in colorectal cancer cells.

In this study, we confirmed that TJE negatively regulated cancer cell viability. Then, we showed that TJE reduced cell viability dose-dependently. Also, it induced apoptotic cell 
A

A

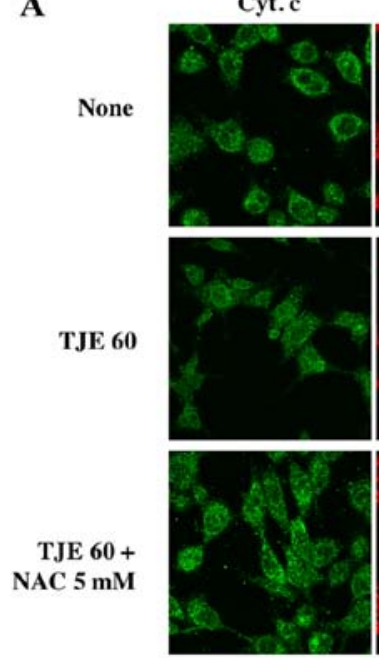

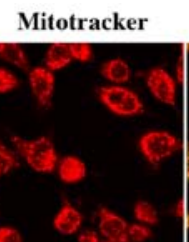
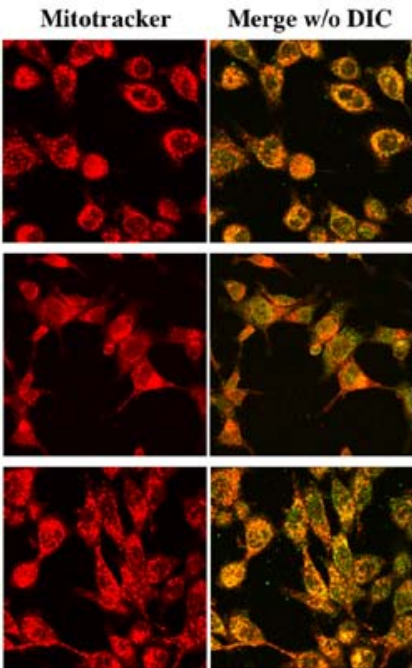

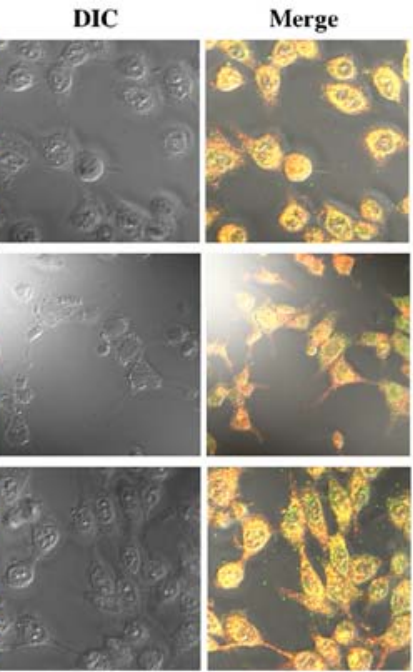

B
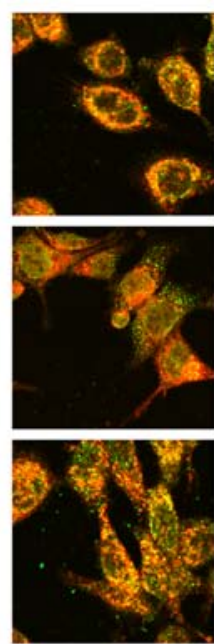

Figure 5. TJE regulates cytochrome $c$ translocation to the cytoplasm. (A) Cells were treated with TJE after 5 mM NAC for 30 min. Pre-stained with mitotracker before fixiation and permeabilization of cells and it was reacted with specific antibody. Florescence detected by confocal microscope. Cell count was confirmed by DIC image. Magnification, x400. (B) Magnified image of merged image. Magnification, x600.

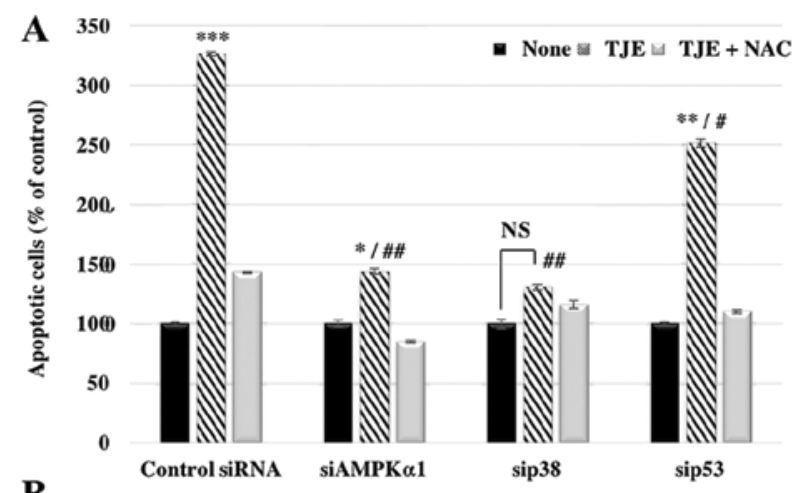

B 160 NS None - TJE $\triangle$ TJE + NAC

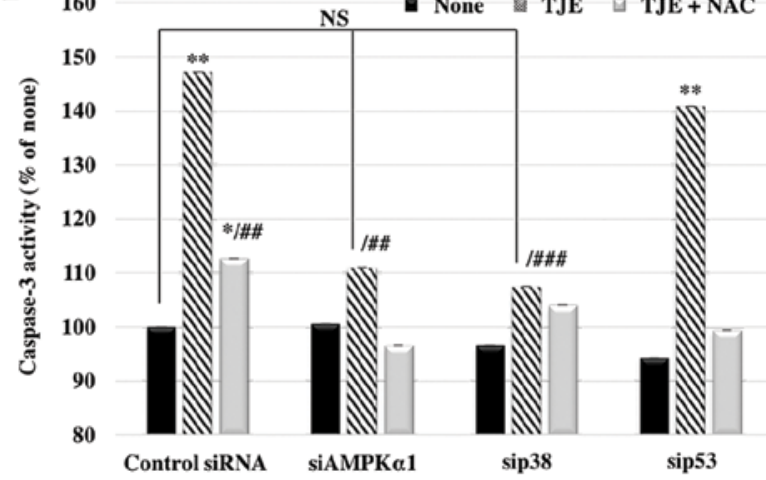

$\mathbf{E}$

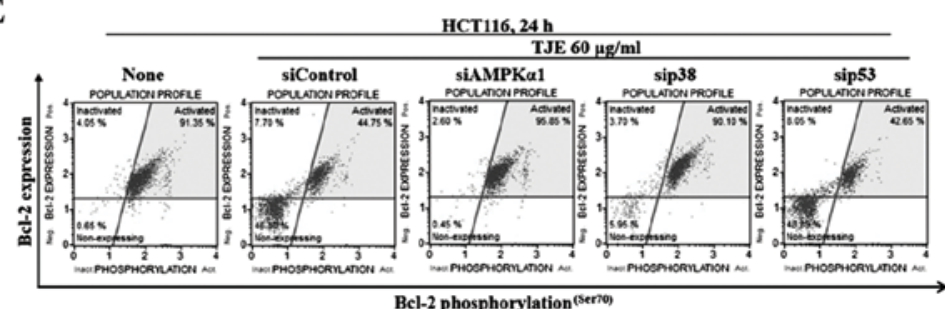

C

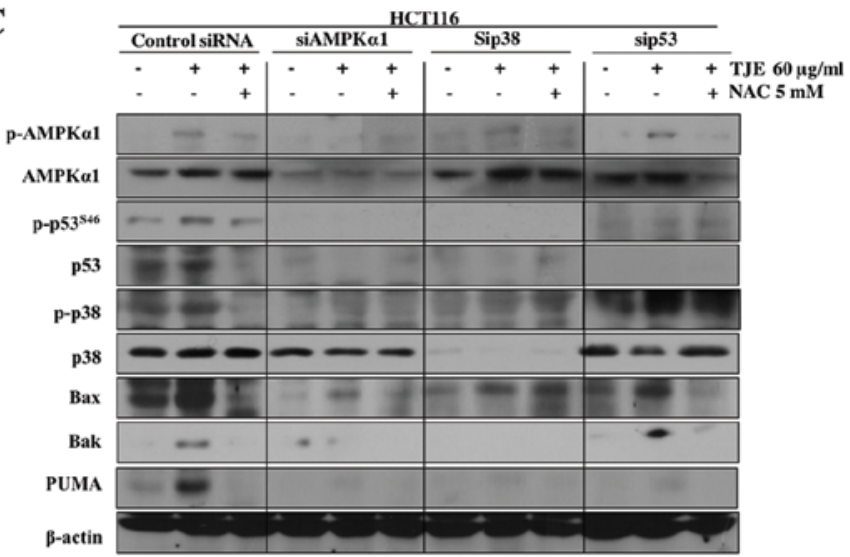

D
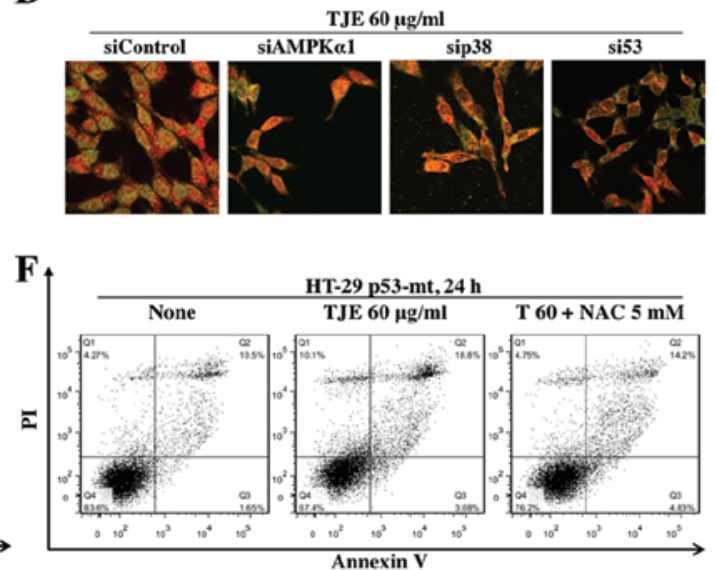

Figure 6. TJE induces apoptosis via the AMPK/p38 MAPK signaling pathway in a p53-independent manner. Cells were transfected with AMPKa1,p38 and p53 siRNA using DharmaFECT and treated with $60 \mu \mathrm{g} / \mathrm{ml} \mathrm{TJE}$ for $6 \mathrm{~h}$ after being pretreated with NAC $5 \mathrm{mM}$ for $30 \mathrm{~min}$. (A) Apoptotic cell death was measured by Annexin V/PI staining and flow cytometry. ${ }^{* *} \mathrm{P}<0.01$ and ${ }^{* * * *} \mathrm{P}<0.001$ compared to control; ${ }^{*} \mathrm{P}<0.05$ and ${ }^{\# \#} \mathrm{P}<0.01$ compared to TJE treated only groups. NS, not significant (each experiment's n=3). (B) Caspase-3 activities were measured by caspase-3 activity assay. ${ }^{*} \mathrm{P}<0.05$ and ${ }^{* * *} \mathrm{P}<0.01$ compared to control; ${ }^{*} \mathrm{P}<0.05$, ${ }^{\# \#} \mathrm{P}<0.01$ and ${ }^{\# \# \#} \mathrm{P}<0.001$ compared to TJE treated only groups. NS, not significant (each experiment $n=3$ ). (C) The protein levels of p-AMPK, p-p38, p-p53 and apoptosis related-proteins were examined by western blotting. (D) Cytochrome $c$ translocation to cytoplasm were detected by a confocal microscope, green fluorescence is cytochrome $c$ and red fluorescence is Mitotracker. (E) Bcl-2 activation was measured by Muse cell analyzer. (F) Measurement of apoptotic cell death in HT-29 colon cancer cells, which are p53 mutant cell line. 

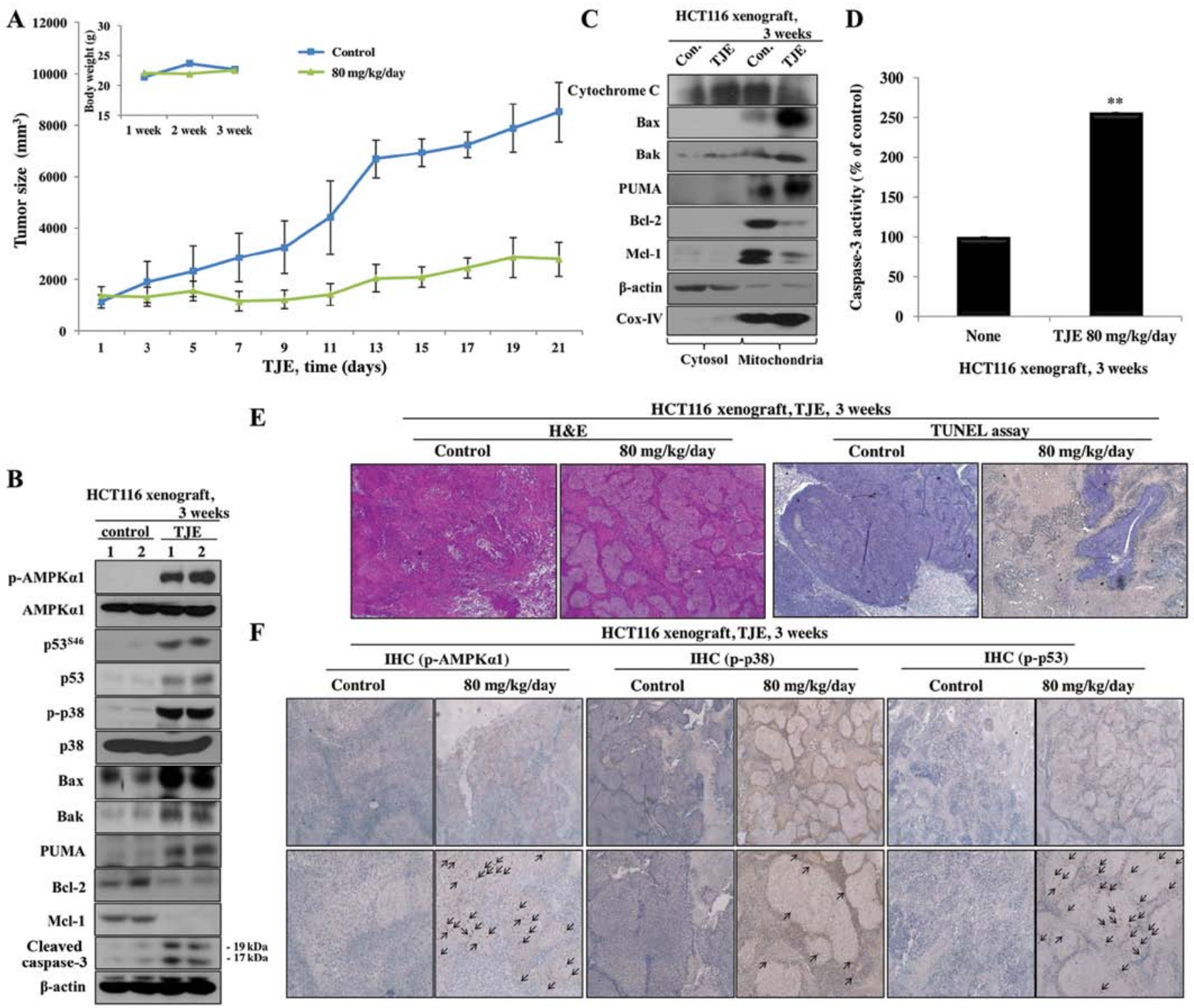

Figure 7. TJE induces cell death through regulation of intracellular signaling pathways in an HCT116 xenograft model. (A) Measurement of tumor size and mouse weight. (B and C) Analyzed protein levels by western blotting. Tissue samples were homogenized in RIPA lysis buffer and neutralization of protein levels by Bradford assay. Mitochondria/cytosol protein fraction executed like a in vitro experiment. (D) Caspase-3 activities were measured by caspase-3 activity assay. ${ }^{* *} \mathrm{P}<0.01$ compared to control. (E) H\&E staining (left panel) and TUNEL assay (right panel). Magnification, $\mathrm{x} 200$. (F) Specific proteins immunohistochemical staining assay. Upper panels were magnified x200 and lower panels x400. Arrows indicate positive reaction to specific proteins.

death by altering the mitochondrial membrane potential and regulating apoptosis related-proteins including Bax, Bak and PUMA. Induction of intracellular ROS in cancer cells by treatment with natural compounds is an appealing option in the development of anticancer agents. Increasing ROS by treatment with natural products not only controls the cell cycle but also induces apoptotic cell death by regulating intracellular signaling molecules such as the Bcl-2 family and caspases $(12,13,28,32-35)$. Thus, we hypothesized that TJE treatment effects cancer cells through an increase in intracellular ROS. Indeed, our results showed that treatment of cancer cells with TJE induces intracellular ROS and affects apoptosis via a reduction in the mitochondrial outer membrane potential through the regulation of protein signaling.

Previous study demonstrated that AMPK activation by ROS induces apoptosis via the ASK1/p38 MAPK pathway in MCF-7 breast cancer cells (35). In the present study, we found that activation of p38 MAPK by phosphorylation of AMPK regulates the mitochondrial membrane potential and induces apoptosis in a p53-independent manner (28). p53 is known to be involved in cancer cell death and arrest of abnormal cellular proliferation (36-39). However, $\sim 50 \%$ of cancer cells have p53 mutations (40). Thus, a p53-independent method of inducing apoptosis would be extremely valuable in cancer treatment. Our results showed that TJE regulates the AMPK/ p38 MAPK signaling pathway and induces apoptosis via regulation of the mitochondrial outer membrane potential and translocation of pro-apoptotic proteins to the mitochondria. When we silenced AMPK and p38 using specific siRNAs, TJE did not affect apoptotic cell death or pro-apoptotic protein expression. Interestingly, in cells transfected with p53 siRNA, apoptosis was induced and apoptosis-related proteins were affected, as in cells treated with only TJE. Moreover, in cells in which AMPK and p38 MAPK were 
silenced, p53 was not activated. Previous studies found that p38 MAPK activation may be regulated by p53 expression and activation via downstream signaling pathways $(41,42)$. Also, the AMPK/p38 MAPK pathway controls apoptosis-related protein expression and induces apoptotic cell death without $\mathrm{p} 53$ activation (28). From our results and those of previous studies, we conclude that TJE induces apoptosis and downregulates the mitochondrial outer membrane potential via the AMPK/ p38 MAPK signaling pathway in a p53-indepent manner.

As in our in vitro studies, TJE induced apoptosis in a mouse xenograft model. The rate of tumor growth was reduced in the TJE-injected group as compared with the control group. Moreover, the TJE-treated group exhibited an increase in pro-apoptosis protein expression and translocation to the mitochondria. Thus, our in vivo studies confirm that TJE regulates the AMPK/p38 MAPK signaling pathway.

In conclusion, we demonstrated that TJE, a natural compound, has potential as an anticancer agent and may provide a substitute for chemotherapeutic drugs.

\section{Acknowledgements}

This study was supported by the 2016 Hannam University Research Fund.

\section{References}

1. Jemal A, Bray F, Center MM, Ferlay J, Ward E and Forman D: Global cancer statistics. CA Cancer J Clin 61: 69-90, 2011.

2. Jemal A, Center MM, DeSantis C and Ward EM: Global patterns of cancer incidence and mortality rates and trends. Cancer Epidemiol Biomarkers Prev 19: 1893-1907, 2010.

3. Center MM, Jemal A and Ward E: International trends in colorectal cancer incidence rates. Cancer Epidemiol Biomarkers Prev 18: 1688-1694, 2009.

4. Parkin DM, Whelan SL, Ferlay J and Storm H (eds): Cancer Incidence in Five Continents. Vol I to VIII. Cancer Base 7. IARC Press, Lyon, 2005.

5. Ito $\mathrm{Y}$, Ioka $\mathrm{A}$, Tanaka $\mathrm{M}$, Nakayama $\mathrm{T}$ and Tsukuma $\mathrm{H}$ : Trends in cancer incidence and mortality in Osaka, Japan: Evaluation of cancer control activities. Cancer Sci 100: 2390-2395, 2009.

6. Giovannucci E: Modifiable risk factors for colon cancer. Gastroenterol Clin North Am 31: 925-943, 2002.

7. Kushi LH, Byers T, Doyle C, Bandera EV, McCullough M, McTiernan A, Gansler T, Andrews KS and Thun MJ; American Cancer Society 2006 Nutrition and Physical Activity Guidelines Advisory Committee: American Cancer Society Guidelines on Nutrition and Physical Activity for cancer prevention: Reducing the risk of cancer with healthy food choices and physical activity. CA Cancer J Clin 56: 254-281, quiz 313-314, 2006

8. Colditz GA, Sellers TA and Trapido E: Epidemiology - identifying the causes and preventability of cancer? Nat Rev Cancer 6: 75-83, 2006.

9. Pan SY, Zhou SF, Gao SH, Yu ZL, Zhang SF, Tang MK, Sun JN, Ma DL, Han YF, Fong WF, et al: New perspectives on how to discover drugs from Herbal medicines: CAM's outstanding contribution to modern therapeutics. Evid Based Complement Alternat Med 2013: 627375, 2013.

10. Prindull G: Apoptosis in the embryo and tumorigenesis. Eur J Cancer 31A: 116-123, 1995.

11. Meier P, Finch A and Evan G: Apoptosis in development. Nature 407: 796-801, 2000.

12. Lee YK, Park SY, Kim YM, Kim DC, Lee WS, Surh YJ and Park OJ: Suppression of mTOR via Akt-dependent and -independent mechanisms in selenium-treated colon cancer cells: Involvement of AMPKalpha1. Carcinogenesis 31: 1092-1099, 2010

13. Chien SY, Wu YC, Chung JG, Yang JS, Lu HF, Tsou MF, Wood WG, Kuo SJ and Chen DR: Quercetin-induced apoptosis acts through mitochondrial- and caspase-3-dependent pathways in human breast cancer MDA-MB-231 cells. Hum Exp Toxicol 28: 493-503, 2009.
14. Adams JM and Cory S: Life-or-death decisions by the Bcl-2 protein family. Trends Biochem Sci 26: 61-66, 2001.

15. Harris $\mathrm{MH}$ and Thompson CB: The role of the Bcl-2 family in the regulation of outer mitochondrial membrane permeability. Cell Death Differ 7: 1182-1191, 2000.

16. Martinou JC and Green DR: Breaking the mitochondrial barrier. Nat Rev Mol Cell Biol 2: 63-67, 2001.

17. Jia L, Macey MG, Yin Y, Newland AC and Kelsey SM: Subcellular distribution and redistribution of Bcl-2 family proteins in human leukemia cells undergoing apoptosis. Blood 93: 2353-2359, 1999.

18. Griffin DE and Hardwick JM: Regulators of apoptosis on the road to persistent alphavirus infection. Annu Rev Microbiol 51: 565-592, 1997.

19. Hsu YT, Wolter KG and Youle RJ: Cytosol-to-membrane redistribution of Bax and Bcl-X(L) during apoptosis. Proc Natl Acad Sci USA 94: 3668-3672, 1997.

20. Luo X, Budihardjo I, Zou H, Slaughter C and Wang X: Bid, a $\mathrm{Bcl} 2$ interacting protein, mediates cytochrome $c$ release from mitochondria in response to activation of cell surface death receptors. Cell 94: 481-490, 1998.

21. Li H, Zhu H, Xu CJ and Yuan J: Cleavage of BID by caspase 8 mediates the mitochondrial damage in the Fas pathway of apoptosis. Cell 94: 491-501, 1998.

22. Mikhailov V, Mikhailova M, Pulkrabek DJ, Dong Z, Venkatachalam MA and Saikumar P: Bcl-2 prevents Bax oligomerization in the mitochondrial outer membrane. J Biol Chem 276: 18361-18374, 2001.

23. Antonsson B, Montessuit S, Lauper S, Eskes R and Martinou JC: Bax oligomerization is required for channel-forming activity in liposomes and to trigger cytochrome $c$ release from mitochondria. Biochem J 345: 271-278, 2000.

24. Antonsson B, Montessuit S, Sanchez B and Martinou JC: Bax is present as a high molecular weight oligomer/complex in the mitochondrial membrane of apoptotic cells. J Biol Chem 276: 11615-11623, 2001.

25. Sundararajan R and White E: E1B 19K blocks Bax oligomerization and tumor necrosis factor alpha-mediated apoptosis. J Virol 75: 7506-7516, 2001.

26. Degterev A, Boyce M and Yuan J: A decade of caspases. Oncogene 22: 8543-8567, 2003

27. Kim GT, Lee SH and Kim YM: Torilis japonica extract, a new potential EMT suppressor agent by regulation of EGFR signaling pathways. Int J Oncol 45: 1673-1679, 2014.

28. Kim GT, Lee SH, Kim JI and Kim YM: Quercetin regulates the sestrin 2-AMPK-p38 MAPK signaling pathway and induces apoptosis by increasing the generation of intracellular ROS in a p53-independent manner. Int J Mol Med 33: 863-869, 2014.

29. Lee YK, Park SY, Kim YM, Lee WS and Park OJ: AMP kinase/cyclooxygenase-2 pathway regulates proliferation and apoptosis of cancer cells treated with quercetin. Exp Mol Med 41: 201-207, 2009.

30. Gibellini L, Pinti M, Nasi M, Montagna JP, De Biasi S, Roat E, Bertoncelli L, Cooper EL and Cossarizza A: Quercetin and cancer chemoprevention. Evid Based Complement Alternat Med 2011: 591356, 2011.

31. Weidner C, Rousseau M, Micikas RJ, Fischer C, Plauth A, Wowro SJ, Siems K, Hetterling G, Kliem M, Schroeder FC, et al: Amorfrutin $\mathrm{C}$ induced apoptosis and inhibits proliferation in colon cancer cells through targeting mitochondria. J Nat Prod 79: 2-12, 2016

32. Zhang X, Chen M,Zou P, Kanchana K, Weng Q, Chen W, Zhong P, Ji J, Zhou H, He L, et al: Curcumin analog WZ35 induced cell death via ROS-dependent ER stress and G2/M cell cycle arrest in human prostate cancer cells. BMC Cancer 15: 866, 2015.

33. He G,He G, Zhou R, Pi Z, Zhu T, Jiang L and Xie Y: Enhancement of cisplatin-induced colon cancer cells apoptosis by shikonin, a natural inducer of ROS in vitro and in vivo. Biochem Biophys Res Commun 469: 1075-1082, 2016.

34. Tanigawa S, Fujii M and Hou DX: Stabilization of p53 is involved in quercetin-induced cell cycle arrest and apoptosis in HepG2 cells. Biosci Biotechnol Biochem 72: 797-804, 2008.

35. Lee YK, Hwang JT, Kwon DY, Surh YJ and Park OJ: Induction of apoptosis by quercetin is mediated through AMPKalpha1/ASK1/ p38 pathway. Cancer Lett 292: 228-236, 2010.

36. Bouchet BP, Caron de Fromentel C,Puisieux A and Galmarini CM: p53 as a target for anticancer drug development. Crit Rev Oncol Hematol 58: 190-207. 2006

37. Moll UM, Marchenko N and Zhang XK: p53 and Nur77/TR3 - transcription factors that directly target mitochondria for cell death induction. Oncogene 25: 4725-4743, 2006. 
38. Gorgoulis VG, Vassiliou LV, Karakaidos $\mathrm{P}$, Zacharatos $\mathrm{P}$, Kotsinas A,Liloglou T, Venere M, Ditullio RA Jr, Kastrinakis NG, Levy B, et al: Activation of the DNA damage checkpoint and genomic instability in human precancerous lesions. Nature 434: 907-913, 2005

39. Oren M: Decision making by p53: Life, death and cancer. Cell Death Differ 10: 431-442, 2003.

40. Olivier M, Hollstein M and Hainaut P: TP53 mutations in human cancers: Origins, consequences, and clinical use. Cold Spring Harb Perspect Biol 2: a001008, 2010.
41. Cuadrado A, Lafarga V, Cheung PC, Dolado I, Llanos S, Cohen P and Nebreda AR: A new p38 MAP kinase-regulated transcriptional coactivator that stimulates p53-dependent apoptosis. EMBO J 26: 2115-2126, 2007.

42. Sanchez-Prieto R, Rojas JM, Taya Y and Gutkind JS: A role for the p38 mitogen-acitvated protein kinase pathway in the transcriptional activation of p53 on genotoxic stress by chemotherapeutic agents. Cancer Res 60: 2464-2472, 2000. 